\title{
Correction to: Addition of glyceryl monostearate affects the crystallization behavior and polymorphism of palm stearin
}

\author{
Liyan $\mathrm{Liu}^{1} \cdot \mathrm{Lin} \mathrm{Li}^{1,2} \cdot$ Liting Wan $^{1} \cdot$ Linlu Mao $^{1} \cdot$ Bing $\mathrm{Li}^{1} \cdot \mathrm{Xia} \mathrm{Zhang}^{1}$
}

Published online: 5 January 2020

c) Springer-Verlag GmbH Germany, part of Springer Nature 2020

\section{Correction to: Bioprocess and Biosystems Engineering https://doi.org/10.1007/s00449-019-02251-1}

The article 'Addition of glyceryl monostearate affects the crystallization behavior and polymorphism of palm stearin', written by Liyan Liu, Lin Li, Liting Wan, Linlu Mao, Bing $\mathrm{Li}$, Xia Zhang, was originally published electronically on the publisher's internet portal (currently SpringerLink) on 14 December 2019 with open access. With the author(s)' decision to step back from Open Choice, the copyright of the article changed on 2020 to $($ C Springer-Verlag GmbH Germany, part of Springer Nature 2020 and the article is forthwith distributed under the terms of copyright.

The original article has been corrected.

The original article can be found online at https://doi.org/10.1007/ s00449-019-02251-1.

\section{Bing Li}

bli@scut.edu.cn

$\triangle$ Xia Zhang

cexzhang@scut.edu.cn

1 School of Food Science and Engineering, Guangdong Province Key Laboratory for Green Processing of Natural Products and Product Safety, South China University of Technology, Guangzhou 510640, China

2 School of Chemical Engineering and Energy Technology, Dongguan University of Technology, College Road 1, Dongguan 523808, China
Publisher's Note Springer Nature remains neutral with regard to jurisdictional claims in published maps and institutional affiliations. 